\title{
Adenoid Cystic Carcinoma of Child: A Rare Case
}

\author{
${ }^{1}$ Meera Mathai, ${ }^{2} \mathrm{~J}$ Eugenia Sherubin, ${ }^{3} \mathrm{PG}$ Agnihotri, ${ }^{4} \mathrm{GS}$ Sangeetha
}

\section{ABSTRACT}

Adenoid cystic carcinoma (ACC) is the second most common malignant tumor affecting both major and minor salivary glands. Clinically, it is a slowly growing tumor with high propensity for local invasion, recurrence and distant metastasis. It is predominantly seen in the fifth and sixth decades of life. Here, we report a rare case of ACC affecting the right maxilla of a 12-year-old girl.

Keywords: Adenoid cytic carcinoma, Child, Maxilla.

How to cite this article: Mathai M, Sherubin JE, Agnihotri PG, Sangeetha GS. Adenoid Cystic Carcinoma of Child: A Rare Case. Int J Clin Pediatr Dent 2014;7(3):206-208.

Source of support: Nil

Conflict of interest: None

\section{INTRODUCTION}

Adenoid cystic carcinoma (ACC) was first described by Robin et al in 1853. In 1859, Billroth suggested an alternate nomenclature 'cylindroma', for its cribriform appearance formed by tumor cells around cylindrical pseudolumina. ${ }^{1}$ However, the term ACC which is widely accepted and currently in use was suggested by Spies in $1930 .^{2}$ Adenoid cystic carcinoma accounts for $22 \%$ of all salivary gland malignancies and is one of the most common malignant tumors of the minor salivary glands with palate being the most common site. ${ }^{2,3}$ It is predominantly seen among women in fifth and sixth decade of life. ${ }^{2,3}$ Adenoid cystic carcinoma is well known for its prolonged clinical course and tendency for delayed onset of distant metastases. The tumor has a well-described histopathologic appearance with certain features that may predict its prognosis. ${ }^{3}$ Treatment of these tumors includes: surgical excision and postoperative radiation. The role of chemotherapy for metastatic ACC is still controversial. ${ }^{4,7}$

\footnotetext{
${ }^{1}$ Postgraduate Student, ${ }^{2}$ Reader, ${ }^{3}$ Professor and Head ${ }^{4}$ Senior Lecturer

${ }^{1-4}$ Department of Oral Medicine and Radiology, Sree Mookambika Institute of Dental Sciences, Kanyakumari, Tamil Nadu, India

Corresponding Author: Meera Mathai, Postgraduate Student, Department of Oral Medicine and Radiology, Sree Mookambika Institute of Dental Sciences, Kanyakumari, Tamil Nadu, India, Phone: 08281538491, e-mail: drmeeramathai@ gmail.com
}

\section{CASE REPORT}

A 12-year-old girl was referred to our department of oral medicine and radiodiagnosis for the evaluation of a swelling in the right posterior maxilla since 2 months. The swelling was initially asymptomatic and eventually developed dull and intermittent pain. Intraoral examination revealed a well-defined swelling of size $5 \times 4 \mathrm{~cm}$ in the right posterior maxilla, extending anteriorly up to the distal aspect of 13 , posteriorly covering the hamular notch and medially involving the soft palate (Fig. 1). The tooth 17 in relation to the swelling was found to be missing. The mucosa over the swelling appeared smooth and bluish in the anterior aspect and erythematous over the posterior aspect. On palpation, the swelling was tender and rubbery in consistency. There were no palpable regional lymph nodes. Patient's medical history was unremarkable with all biochemical examination results within normal limits. Considering the age and site, we made a clinical diagnosis of mucoepidermoid carcinoma of right maxilla with a differential diagnosis of ACC. The patient was subjected for radiographic examination (Fig. 2). Computed tomography (CT) showed a welldemarcated lobulated minimally enhancing soft-tissue density of mass $4.5 \times 2.7 \times 2.2 \mathrm{~cm}$ in the posterior half of right hard palate with thick enhancing septations causing scalloping and thinning of palatine bone-favoring a diagnosis of malignant salivary gland tumor.

The histopathological examination of the specimen subjected after an incisional biopsy showed cribriform or Swiss Cheese pattern of tumor cells and basaloid epithelial cells rendering a final diagnosis of ACC (Fig. 3). Following which, the patient was subjected for a whole body CT screening to rule out metastasis and magnetic resonance imaging (MRI) head and neck to rule out perineural invasion.

The patient was treated with subtotal maxillectomy of right side followed by placement of surgical stent with surgical site packed with ribbon gauze impregnated with iodoform and glycerin (Fig. 4). Patient was reviewed after 2 weeks, patient made an unremarkable recovery. Patient is under our follow-up.

\section{DISCUSSION}

Tumors of salivary glands are rare in children and malignant tumors are even more so ${ }^{5}$. Although ACC was thought to be mainly a disease of the elderly, a recent 


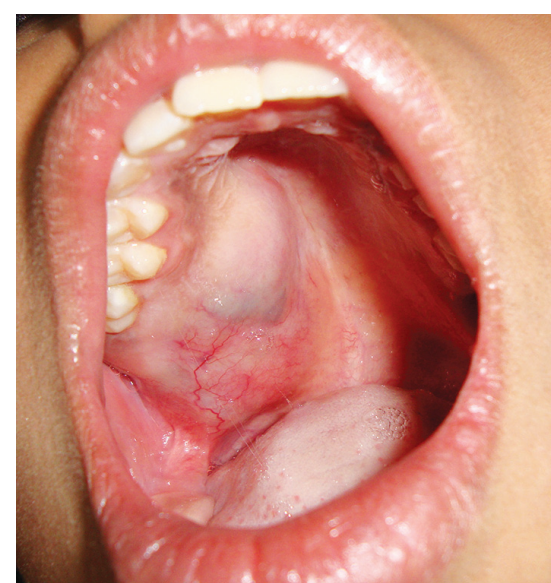

Fig. 1: Intraoral photograph of swelling

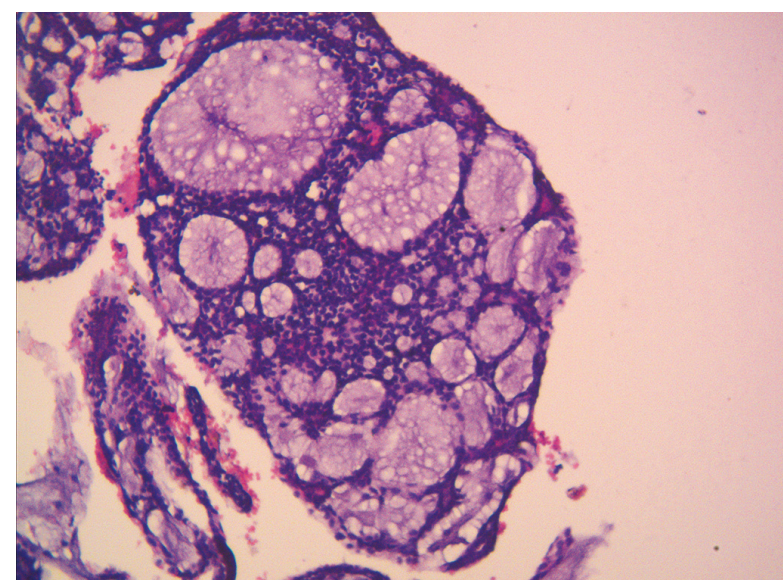

Fig. 3: Histopathological slide

review reports an age range of 10 to 96 years. According to the gender predilection, even though few authors, such as Evesson and Cawson found a female predilection, majority of researchers in the literature have reported an equal distribution in both genders. ${ }^{1}$ Regarding the etiology, there is neither a universally accepted predisposing factors nor a family tendency for the development of ACC. ${ }^{6}$

Clinically, ACC always has an initial period of asymptomatic slow and indolent growth, where majority of the tumor goes unnoticed until it invades the local nerves and structures causing a delay in seeking treatment. Hence, most patients present with locally invasive disease at the initial visit itself. Even though this tumor grows slowly it widely infiltrates with a characteristic mode of spread. It has a tendency for perineural spread accounting for pain in about $50 \%$ of cases. ${ }^{3}$ The propensity of this tumor to invade bone and spread along the base of the skull results in extensive intracranial invasion and involvement of the cranial nerves. Extensive intracranial invasion is the major cause of death in these tumors. ${ }^{4}$

Radiological investigations, especially CT is important to delineate the tumor, to plan extent of surgery and to look out for recurrences as a follow-up postoperatively. Pulmonary and skeletal surveys are important to rule

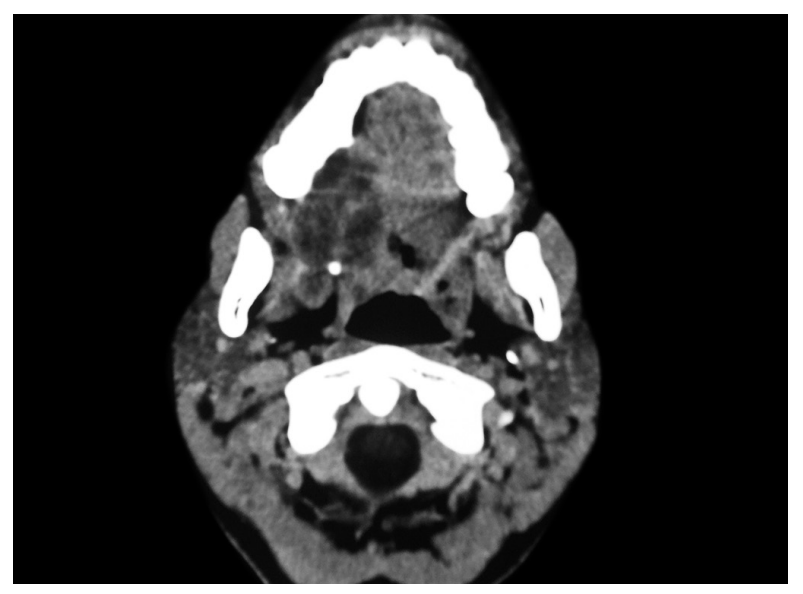

Fig. 2: Computed tomography image of the lesion

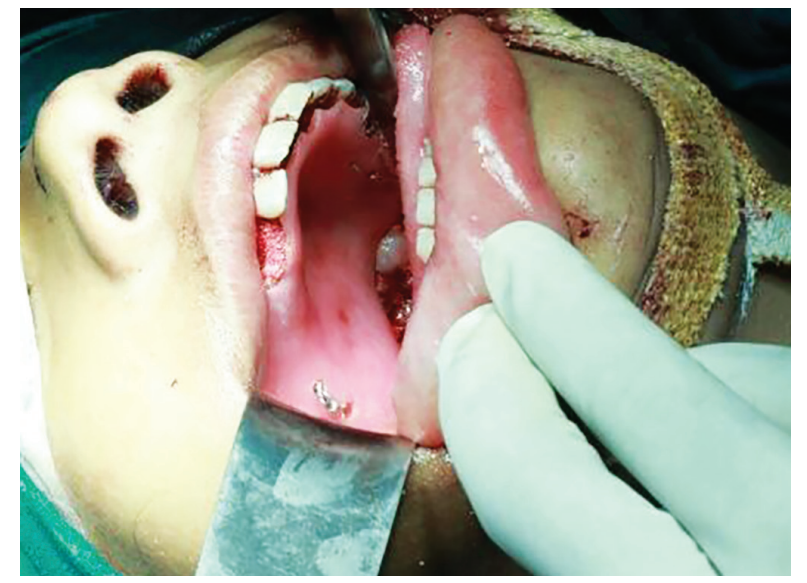

Fig. 4: Stent placed after resection

out distant metastasis. ${ }^{4}$ Regarding metastasis of ACC, lymphatic spread is rare. In longstanding cases, distant metastasis occurs via bloodstream to lungs and bones. Most cases of metastatic ACC remain asymptomatic for a long time. Distant metastasis can appear years or even decades after the initial diagnosis.

Final diagnosis of ACC is primarily based on its characteristic histological features which play a significant role not only in diagnosing the tumor but also in determining treatment and prognosis. Among the three forms, cribriform, tubular and solid, solid subtype is considered to be the most aggressive tumor. ${ }^{4}$

Treatment of these tumors includes: surgical excision and postoperative radiation. The role of chemotherapy for metastatic ACC is still controversial. ${ }^{4}$ The clinical course of the disease is heterogeneous with some patients surviving decades and others surviving only months. ${ }^{3}$ The prognosis depends on factors like solid histological type, perineural spread, distant metastasis and recurrent local lesions. ${ }^{89}$ The microinvasion of bones, which is clinically and radiologically undetectable, frequently results in local recurrences even after surgery. ${ }^{4}$ Hence, a close surveillance and a long-term follow-up is mandatory in the management of this disease. 


\section{CONCLUSION}

Adenoid cystic carcinoma is one of the most biologically destructive and unpredictable tumor of the minor salivary glands occurring predominantly in the fifth and sixth decades of life. Its occurrence in children is extremely rare. Hence, an awareness among the dental fraternity about the existence of this disease in child population can ensure a better survival period for these patients and enhance their quality of life by our early diagnosis and interventions.

\section{REFERENCES}

1. Sekhar, Augustin D, Murali S. Adnoid cyatic carcinoma of palate: a case report with review of literature. JIADS 2010;1(4): 155-158.

2. DN, Metha, Parikh SJ. Adenoid cystic carcinoma of palate. J Natural Sci Biol Med 2013 Jan;4(1):249-252.
3. Jaso J, Reenu Malhotral J. Adenoid cystic carcinoma: resident short review. Arch Pathol Lab Med 2011;135:511-515.

4. Dutta NN, Baruah R, Das L. Adenoid cystic carcinoma-clinical presentation and cytological diagnosis: Ind J Otolaryngol Head Neck Surg 2002;54(1):62-64.

5. Danziger $H$. Adenoid cystic carcinoma of submaxillary gland in 8-month-old infant. Canad Med Ass K 1964;91(3):759-761.

6. Orhan K, Yuksel Y, Gorur D. Solid adenoid cystic carcinoma of maxilla: a case report. Clinical Dentistry and Research 2006; 30:42-47.

7. Choudhary $\mathrm{K}$, et al. Adenoid cystic carcinoma of the hard palate: a case report with therapeutic and prognostic aspects. Ind J Oral Sci 2012;3(2):113-116.

8. Sharma K, et al. A retrospective study of 18 cases of adenoid cystic cancer in a tertiary care centre in Delhi. Ind J Cancer 2012 Oct-Dec;47(4)113-116.

9. Khafif A, et al. Adenoid cystic carcinoma of salivary glands: a 20-year review with long-term follow-up. ENT J 2005;84(10): 662-667. 